\title{
Influence of Mn doping on the microstructure and optical property of $\mathrm{ZnO}$
}

\author{
K.Rajendran ${ }^{\mathrm{a}}$, S.Banerjee ${ }^{\mathrm{b}}$, S.Senthilkumaar ${ }^{\mathrm{c}}$,T.K.Chini ${ }^{\mathrm{b}}$, V.Sengodan ${ }^{\mathrm{d}}$, \\ ${ }^{a}$ Department of Electronics and Communication Systems, Sri Krishna Arts and Science \\ College, Coimbatore, India \\ ${ }^{\mathrm{b}}$ Surface Physics Division, Saha Institute of Nuclear Physics, 1/AF Bidhannagar, Kolkata, \\ India \\ ${ }^{c}$ Department of Chemistry, Faculty of Engineering, PSG College of Technology, \\ Coimbatore, India \\ ${ }^{\mathrm{d}}$ Department of Electronics, SNR Sons College, Coimbatore, India
}

\begin{abstract}
Undoped and $\mathrm{Mn}$ doped $\mathrm{ZnO}$ samples with different percentage of Mn content (1 mol\%, $2 \mathrm{~mol} \%$ and $3 \mathrm{~mol} \%$ ) were synthesized by a simple solvo-thermal method. We have studied the structural, chemical and optical properties of the samples by using x-ray diffraction (XRD), scanning electron microscopy (SEM), energy dispersive x-ray (EDX) analysis, Fourier transform infrared (FTIR) spectroscopy and UV-VIS spectroscopy. The XRD spectra show that all the samples are hexagonal wurtzite structures. The lattice parameters calculated for the $\mathrm{Mn}$ doped $\mathrm{ZnO}$ from the $\mathrm{XRD}$ pattern were found to be slightly larger than those of the undoped $\mathrm{ZnO}$, which indicates substitution of $\mathrm{Mn}$ in $\mathrm{ZnO}$ lattice. SEM photograph shows the grain size of undoped $\mathrm{ZnO}$ is bigger than the $\mathrm{Mn}$ doped $\mathrm{ZnO}$ 's indicating hindrance of grain growth upon Mn doping. As the Mn doping increases the optical band gap decreases for the range of Mn doping reported here.
\end{abstract}

Keywords: Solvo-thermal; Mn doped ZnO; Optical properties

*Corresponding author E-mail:sskumaarpsg@gmail.com 


\section{Introduction}

$\mathrm{ZnO}$ materials have received broad attention due to their well-known performance in electronics, optics and photonics [1,2]. The device application of micro and nanostructure of $\mathrm{ZnO}$ is one of the major focuses among researchers to diminish the size of the device in order to achieve higher speeds in its electrical transport and also to study the effect of confinement on optical properties. $\mathrm{ZnO}$ is a direct wide band gap $\left(\mathrm{E}_{\mathrm{g}} \sim 3.3\right.$ $\mathrm{eV}$ at room temperature) n-type semiconductor with optical transparency in the visible range. This provides opportunities to develop transparent electronics, optoelectronics and integrated sensors [3].

The interest in doping $\mathrm{ZnO}$ is to explore the possibility of tailoring its electrical, magnetic and optical properties [4-8]. Such films could be used in areas like electronics, optoelectronics and could be a potential challenger to other oxides such as $\mathrm{SnO}_{2}$ and Indium-Tin Oxides (ITO). The transition metal doped $\mathrm{ZnO}$ has the potential to be a multifunctional material with coexisting magnetic, semi-conducting and optical properties [9]. The samples can be synthesized in the bulk and thin film forms and a wide range of magnetic properties including room temperature ferromagnetism have been reported [10-11] and can be applied to short-wave magneto-optical devices [12 ].

The doping of transition metal elements into $\mathrm{ZnO}$ offers a feasible means of fine tuning the band gap to make use as UV detector and light emitters. It has been observed earlier by other groups $[13,14]$ that upon $\mathrm{Mn}$ doping in $\mathrm{ZnO}$ the band gap reduces for low concentration doping $(<3 \mathrm{~mol} \%$ of $\mathrm{Mn}$ ) and for higher concentration $(>3 \mathrm{~mol} \%$ ) the band gap increases as expected on the basis of virtual crystal approximation (VCA) because of the band gap of the $\mathrm{MnO} \sim 4.2 \mathrm{eV}$. In many dilute magnetic semiconductor 
(DMS) systems such deviation from the linear monotonic increase in the form of "band gap bowing" has been observed [15-21]. For the low concentration Mn doping the reduction in the band gap has been theoretically explained as a consequence of exchange interaction between $\mathrm{d}$ electrons of the transition metal ions $(\mathrm{Mn})$ and the $\mathrm{s}$ and $\mathrm{p}$ electron of the host band.

The aim of this work is to evaluate the effect of Mn doping on the microstructure, grain growth and the optical properties of the powder grown by simple solvo-thermal method and thin films prepared by dip coating method for the range of Mn doping $\leq 3$ mol\%. The EDX analysis shows the excellent oxide formation, wherein dopant ions are present in the host crystal lattice. The FTIR analysis shows the stretching vibrations and the oxide formations. We have measured the energy gap of the different concentration of Mn doped ZnO samples from the UV-VIS absorption spectra and it shows the decrease in band gap upon Mn doping as expected.

\section{Experimental details:}

\subsection{Materials}

The starting materials of analytical grade were zinc acetate dihydrate and manganese acetate tetrahydrate supplied by Lancaster and used as such. Reagent grade absolute ethanol was obtained from Changshu Yangyuan chemical, China and triply distilled.

\subsection{Synthesis}

The experimental flow chart for the synthesis of $\mathrm{ZnO}$ and $\mathrm{Mn}$ doped $\mathrm{ZnO}$ is shown in Fig.1. Undoped $\mathrm{ZnO}$ and different concentration of $\mathrm{Mn}$ doped $\mathrm{ZnO}$ were synthesized through a simple solvo-thermal process (this is also referred as sol-gel by 
some authors). The undoped $\mathrm{ZnO}$ was prepared using zinc acetate $\mathrm{Zn}(\mathrm{CH} 3 \mathrm{COO})_{2} \cdot 2 \mathrm{H}_{2} \mathrm{O}$ (14g) and ethanol (sample ' $\mathrm{a}$ '). For preparing $\mathrm{Mn}$ doped $\mathrm{ZnO}$ the zinc acetate $\mathrm{Zn}(\mathrm{CH} 3 \mathrm{COO})_{2} \cdot 2 \mathrm{H}_{2} \mathrm{O} \quad(14 \mathrm{~g})$ and $1 \mathrm{~mol} \%, 2 \mathrm{~mol} \%, 3 \mathrm{~mol} . \%$ of manganese acetate $\mathrm{Mn}(\mathrm{CH} 3 \mathrm{COO})_{2} \cdot 4 \mathrm{H}_{2} \mathrm{O}$ were taken in a round bottom flask and ethanol was slowly added with constant stirring and labeled as sample 'b', 'c' and 'd' respectively. All the mixers were stirred vigorously for $12 \mathrm{~h}$ and the solution obtained was ultrasonicated for $30 \mathrm{~min}$. Thin films were prepared on the cleaned quartz substrate by dipping in the sol with constant retrieving rate of $0.16 \mathrm{~mm} / \mathrm{sec}$ and were annealed at $500^{\circ} \mathrm{C}$ for $1 \mathrm{~h}$.

\subsection{Characterization}

$\mathrm{X}$-ray analyses of the sintered samples were carried out using $\mathrm{CuK}_{\alpha}$ radiation on a powder diffractometer (Schimadzu, Model XRD6000) in the $2 \theta$ range between $10^{\circ}$ and $80^{\circ}$. The chemical compositions and the microstructure of the samples were carried out using energy dispersive $\mathrm{x}$-ray (EDX) analyzer attached with a scanning electron microscope (SEM), model FEI QUANTA 200F. Fourier transform infrared spectroscopy (FTIR) absorption was measured for $\mathrm{KBr}$ supported samples over the frequency range of $4000-400 \mathrm{~cm}^{-1}$ and at a resolution of $4 \mathrm{~cm}^{-1}$, using a model SHIMADZU, FTIR-8400S. Optical transmittance spectra at room temperature of the films have been recorded in the wavelength range of 200 to $2500 \mathrm{~nm}$ using a double beam UV-VIS-NIR Spectrophotometer JASCO, model V-570.

\section{Result and discussion}

Powder $\mathrm{x}$-ray diffraction patterns of undoped $\mathrm{ZnO}$ and $\mathrm{Mn}$ doped $\mathrm{ZnO}$ are shown in Fig.2. The characteristic peaks with high intensities corresponding to the planes (100), (002), (101) and lower intensities at (102), (110), (103), (200), (112) and (201) indicate 
the annealed product is of high-purity hexagonal $\mathrm{ZnO}$ wurtzite structure. It's evident from the XRD data that there are no extra peaks due to manganese metal, other oxides or any zinc manganese phase, indicating that the as-synthesized samples are single phase. The Mn ion was understood to have substituted the $\mathrm{Zn}$ site without changing the wurtzite structure at $500^{\circ} \mathrm{C}$.

The peaks of the diffraction patterns of doped samples are slightly shifted to left as compared to the undoped $\mathrm{ZnO}$. This shows that small variation in the lattice parameters occur as Mn concentration in the sample increases. Table 1 shows that the lattice constants of $\mathrm{Mn}$ doped $\mathrm{ZnO}$ were slightly larger than those of undoped $\mathrm{ZnO}$, because the ionic radius of $\mathrm{Mn}(\mathrm{II})$ (0.66) is larger than that of $\mathrm{Zn}(\mathrm{II})(0.60)$ [12]. The length of both $a$ and $c$ axis expand monotonously with the increasing Mn doping in $\mathrm{ZnO}$. The expansion of the lattice constants and the slight shift of XRD peaks of different concentration of $\mathrm{Mn}$ doped $\mathrm{ZnO}$ indicated that manganese has really doped into the $\mathrm{ZnO}$ structure. The average crystal size (D) was estimated using the Scherrer formula. The crystal size of the undoped $\mathrm{ZnO}$ decreases on doping $1 \mathrm{~mol} \%$ of $\mathrm{Mn}$ and on subsequent doping shows an increasing tendency as shown in table 2 .

Energy dispersive $\mathrm{x}$-ray analysis showed that the amount of Mn element in the sample increased depending on the increasing Mn incorporation in the solution. As a result, $\mathrm{Mn}$ incorporation has a strong effect on the optical, structural and morphological properties of $\mathrm{ZnO}$. The Energy dispersive x-ray analysis shown in Fig.3 (a) consists of $\mathrm{Zn}$ and $\mathrm{O}$ and fig (b)-(d) confirms the presence of manganese in the $\mathrm{ZnO}$ particles and $\mathrm{wt} \%$ are very nearly equal to the nominal value of $\mathrm{Mn}$ in $\mathrm{ZnO}$ (Note: traces of $\mathrm{Al}$ and $\mathrm{C}$ less 
than $0.1 \mathrm{wt} \%$ are observed. The $\mathrm{Al}$ peak may be arising from the sample stub). The table 3 list out the $\mathrm{wt} \%$ of the compounds in undoped $\mathrm{ZnO}$ and $\mathrm{Mn}$ doped $\mathrm{ZnO}$.

SEM photograph shown in Fig. 4 shows the size and distribution of particles in the samples. We observe for undoped $\mathrm{ZnO}$ the grain size is bigger than the $\mathrm{Mn}$ doped $\mathrm{ZnO}$. The SEM investigations of all samples revealed that the crystallites are of nanometer size. The grain growth of $\mathrm{ZnO}$ is hindered upon $\mathrm{Mn}$ doping, but no significant changes of the grain size is observed from SEM images as the Mn concentration is increased.

For FTIR analysis the $\mathrm{KBr}$ pellets are prepared from the undoped and different mol\% of Mn doped $\mathrm{ZnO}$ powders at two set of temperatures $100^{\circ} \mathrm{C}$ and $500^{\circ} \mathrm{C}$, and their spectrum were shown in Fig. 5(a) and Fig.5(b) respectively. The $100^{\circ} \mathrm{C}$ dried samples retains some typical features of an acetate salt. Two principal absorption peaks are observed between 1650 and $1400 \mathrm{~cm}^{-1}$ corresponding to the asymmetric and symmetric stretching of the carboxyl group $(\mathrm{C}=\mathrm{O})$. The broad absorption peaks around $3200 \mathrm{~cm}^{-1}$ and $2550 \mathrm{~cm}^{-1}$ are due to $\mathrm{O}-\mathrm{H}$ stretching and peaks around $2900 \mathrm{~cm}^{-1}$ is due to $\mathrm{C}-\mathrm{H}$ (acetate) stretching. The absorption peaks observed between $2300-2400 \mathrm{~cm}^{-1}$ is because of the existence of $\mathrm{CO}_{2}$ molecule in air. The deformation bands of $\mathrm{C}=\mathrm{O}$ can also be observed around $1000 \mathrm{~cm}^{-1}$ [18]. The $500^{\circ} \mathrm{C}$ annealed samples shows drastic diminishing of carboxylate group $(\mathrm{C}=\mathrm{O})$ and the characteristics peak for the $\mathrm{C}-\mathrm{H}$ (acetate) group, suggesting the loss of acetic acid. Thus on annealing we only observe a very strong band below $500 \mathrm{~cm}^{-1}$ due to the $\mathrm{Zn}-\mathrm{O}$ and $(\mathrm{Zn}, \mathrm{Mn})-\mathrm{O}$ stretching modes.

The optical transmittance of the undoped $\mathrm{ZnO}$ and $\mathrm{Mn}$ doped $\mathrm{ZnO}$ thin films was determined by the spectrophotometer within the wavelength range of $200-2500 \mathrm{~nm}$. For, 
the transmittance measurements, the films were grown on quartz substrate and irradiated at a perpendicular angle of incidence with quartz glass as reference. The typical room temperature transmittance spectra for undoped $\mathrm{ZnO}$ and different concentration of $\mathrm{Mn}$ doped $\mathrm{ZnO}$ are shown in Fig.6. The optical absorption coefficient $(\alpha)$ is evaluated from the transmission spectra using the relation

$$
\alpha=-1 / \mathrm{d} \ln (\mathrm{T})
$$

where $\mathrm{d}$ is the thickness of the film and $\mathrm{T}$ is the transmittance. The optical band gap was evaluated using the relation:

$$
(\alpha h v)^{2}=\mathrm{A}\left(\mathrm{h} v-\mathrm{E}_{\mathrm{g}}\right)
$$

where $\mathrm{A}$ is a constant, $\mathrm{h} v$ the photon energy, and $\mathrm{E}_{\mathrm{g}}$ is the energy gap. The absorption coefficient was a function of photon energy for undoped and $\mathrm{Mn}$ doped $\mathrm{ZnO}$ films. The energy gap, $E_{g}$, is estimated from the intercept of the linear portion of the curve. We observe red shift in the band gap due to $\mathrm{Mn}$ doping in $\mathrm{ZnO}$. We obtained the band gap to be $3.27 \mathrm{eV}$ for undoped $\mathrm{ZnO}$ and it starts decreasing for $1 \mathrm{~mol} \%, 2 \mathrm{~mol} \%$ and $3 \mathrm{~mol} \%$ of Mn doped $\mathrm{ZnO}$ samples as $3.06 \mathrm{eV}, 2.90 \mathrm{eV}$ and $2.78 \mathrm{eV}$ respectively. The decrease in $\mathrm{E}_{\mathrm{g}}$ for increasing Mn content is attributed to the s-d and p-d interactions giving rise to band gap bowing and it has been theoretically explained using second-order perturbation theory [16].

\section{Conclusion}

$\mathrm{ZnO}$ powders containing transition metal $\mathrm{Mn}$ synthesized by a simple solvothermal process correspond to a hexagonal structure similar to that of undoped $\mathrm{ZnO}$. The XRD measurement suggests that $\mathrm{Mn}$ atoms substitute $\mathrm{Zn}$ sites in the crystals without changing the wurtzite structure, but with the lattice parameters varying slightly with the 
extent of doping. We also observed on doping the grain size reduces drastically reducing to nano-scale i.e., doping hinders the grain growth . No secondary phases were observed for the simple synthesis process adapted in the present work for the doped $\mathrm{ZnO}$ samples upto $18.31 \mathrm{wt} \%$ of Mn doping. The FTIR analysis confirms the formation of $\mathrm{ZnO}$ and Mn doped $\mathrm{ZnO}$. The UV-VIS-NIR measurements show the reduction in the band-gap upon Mn doping for concentration of $\mathrm{Mn} \leq 3 \mathrm{~mol} \%$. 


\section{References}

[1] Das sarma S, Spintronics. American Scientist 2001; 89:516-528.

[2] Sharma P, Sreenivas K, Rao KV, Analysis of ultraviolet photoconductivity in $\mathrm{ZnO}$ films prepared by unbalanced magnetron sputtering. J.Appl. Phys. 2003; 93:3963-3970.

[3] Khanna SN, Rao BK, Jena P, Knickelbein M, Ferrimagnetism In $\mathrm{Mn}_{7}$ Cluster. Chemical Phys. Letts. 2003; 378:374-379.

[4] Major, S., Banerjee, A. \& Chopra, K. L. Highly transparent and conducting indium-doped zinc oxide films by spray pyrolysis. Thin Solid Films 1983; 108: 333-340.

[5] Major, S., Banerjee, A., Chopra, K. L. Nagpal KC. Thickness-dependent properties of indium-doped ZnO films. Thin Solid Films 1986; 143:19-30.

[6] Hauffe K, Vierk AL, Electrical conductivity of zinc oxide with foreign oxides. Z. Phys. Chem. 1950;196:160.

[7] Wagner, C., The mechanism of the decomposition of nitrous oxide on zinc oxide catalyst. J. Chem. Phys. 1950; 18:69-71.

[8] Aktaruzzaman, AF, Sharma, GL, Malhotra LK. Electrical, optical and annealing characteristics of $\mathrm{ZnO}: \mathrm{Al}$ films prepared by spray pyrolysis. Thin Solid Films 1991;198:67-74.

[9] Mandal S.K, Nath T.K. Microstructural, magnetic and optical properties of $\mathrm{ZnO}: \mathrm{Mn}(0.01 \leq \mathrm{x} \leq 0.25)$ epitaxial diluted magnetic semiconducting films. Thin solid films. 2006; 515:2535-2541.

[10] Sharma P, Gupta A, Rao KV, Owens FJ, Sharma R, Ahuja R, Osorio Gullen J.M, Johansson B, Gehring G.A, Ferromagnetism above room temperature in bulk and transparent thin films of Mn-doped ZnO. Nature Material 2003; 2:673677.

[11] Kundaliya DC, Ogale SB, Lofland SE, Dhar S, Metting CJ, Shinde SR, Ma Z, Varughese B, Ramanujachary KV, Salamanca-Riba L, Venkatesan T, On the origin of high-temperature ferromagnetism in the low-temperature processed $\mathrm{Mn}-$ Zn-O system. Nature Material 2004; 3:709-714.

[12] Cong CJ, Liao L, Li CJ, Fan LX, Zhang KL. Synthesis, structure and ferromagnetic properties of Mn-doped ZnO nanoparticles. Nanotechnology 2005; 16:981-984.

[13] Venkataprasad Bhat S, Deepak FL. Tuning the bandgap of ZnO by substitution with $\mathrm{Mn}^{2+}, \mathrm{Co}^{2+}$ and $\mathrm{Ni}^{2+}$. Solid State Communications 2005; 135:345-347.

[14] Viswanatha R, Sapra S, Gupta S.S, Satpati B, Satyam PV,.Dev BN, Sarma DD. Synthesis and Characterization of Mn-Doped ZnO Nanocrystals. J.Phys. Chem. B 2004; 108:6303-6310.

[15] Furdyna JK. Diluted magnetic semiconductor. J. Appl. Phys. 1988; 64: R29-R64.

[16] Bylsma RB.; Becker WM.; Kossut J; Debska U. Dependence of energy gap on X and T in Zn1-x Mnx Se: The role of exchange interaction. Phys. Rev. B 1986; 33:8207-8215.

[17] Jimenez-Gonzalez A.E, SotoUrueta A. Jose, Suarez-Para R. Optical and electrical characteristics of aluminum-doped $\mathrm{ZnO}$ thin films prepared by solgel technique. J. Crystal Growth 1998; 192:430-438. 
[18] Alaria J, Turek P, Bernard M, Bouloudenine M, Berbadj A, Brihi N, G. Schmerber, S. Colis, A. Dinia, No ferromagnetism in $\mathrm{Mn}$ doped $\mathrm{ZnO}$ semiconductors. Chemical Physics Letters 2005; 415:337-341.

[19] Hua-Wei Zhang, Wei Shi Er, Zhi-Zhan Chen, Xue-Chao Liu, Bing Xiao, Li-Xin Song. Optical and magnetic resonance investigations of $\mathrm{Zn}_{1-\mathrm{x}} \mathrm{Mn}{ }_{\mathrm{x}} \mathrm{O}$ magnetic semiconductors. J. Magn. Magn. Mater. 2006; 305:377-380.

[20] Hua-Wei Zhang, Er-Wei Shi, Zhi-Zhan Chen, Xue-Chao Liu, Bing Xiao. Magnetism in $\mathrm{Zn}_{1-\mathrm{x}} \mathrm{Mn}_{\mathrm{x}} \mathrm{O}$ crystal prepared by hydrothermal method, Solid state communications. 2006; 137:272-274.

[21] Shinde V.R, Gujar T.P, Lokhande C.D, Mane R.S, Sung-Hwan Han. Mn doped and undoped $\mathrm{ZnO}$ films: A comparative structural, optical and electrical properties study. Mater. chem. and phys. 2006; 96:326-330. 
Table 1: The lattice constants calculated from XRD data of $\mathrm{ZnO}$ (sample a)and different mole $\%$ of Mn doped $\mathrm{ZnO}$ (samples b,c and d)

\begin{tabular}{ccccc}
\hline \multirow{2}{*}{$\begin{array}{c}\text { Lattice } \\
\text { Constants }\end{array}$} & \multirow{2}{*}{$\mathrm{ZnO}$} & \multicolumn{3}{c}{ Different $\mathrm{mol} \% \mathrm{Mn}$ doped $\mathrm{ZnO}$} \\
\cline { 3 - 5 } & & $1 \mathrm{~mol} \% \mathrm{Mn}$ & $2 \mathrm{~mol} \% \mathrm{Mn}$ & $3 \mathrm{~mol} \% \mathrm{Mn}$ \\
\hline $\mathrm{a} \AA$ & 3.248 & 3.255 & 3.270 & 3.277 \\
\hline $\mathrm{c} \AA$ & 5.204 & 5.212 & 5.236 & 5.243 \\
\hline
\end{tabular}


Table 2: Average grain size as a function of $\mathrm{Mn}$ in $\mathrm{ZnO}$ annealed at $500^{\circ} \mathrm{C}$ for $1 \mathrm{~h}$.

\begin{tabular}{ll}
\hline Samples & $\begin{array}{l}\text { Grain Size (D) } \\
\mathrm{nm}\end{array}$ \\
\hline Undoped $\mathrm{ZnO}$ & 19.11 \\
\hline $\begin{array}{l}1 \mathrm{~mol} \% \mathrm{Mn} \\
\text { doped } \mathrm{ZnO}\end{array}$ & 15.45 \\
\hline $\begin{array}{l}2 \mathrm{~mol} \% \mathrm{Mn} \\
\text { doped } \mathrm{ZnO}\end{array}$ & 17.88 \\
\hline $\begin{array}{l}3 \mathrm{~mol} \% \mathrm{Mn} \\
\text { doped } \mathrm{ZnO}\end{array}$ & 18.24 \\
\hline
\end{tabular}


Table 3: The $\mathrm{wt} \%$ are calculated for undoped (sample a) and $\mathrm{Mn}$ doped $\mathrm{ZnO}$ of $1 \mathrm{~mol} \%$, $2 \mathrm{~mol} \%$ and $3 \mathrm{~mol} \%$ (samples b,c and d)

\begin{tabular}{lrrrr}
\hline Element & \multicolumn{1}{c}{ a wt $\%$} & \multicolumn{1}{c}{$\mathrm{bwt} \%$} & $\mathrm{c} \mathrm{wt} \%$ & $\mathrm{dwt} \%$ \\
\hline $\mathrm{O}$ & 14.93 & 14.87 & 14.85 & 14.34 \\
\hline $\mathrm{Mn}$ & --- & 6.54 & 11.59 & 18.31 \\
\hline $\mathrm{Zn}$ & 85.07 & 78.58 & 73.56 & 67.35 \\
\hline Total & 100.00 & 100.00 & 100.00 & 100.00 \\
\hline
\end{tabular}




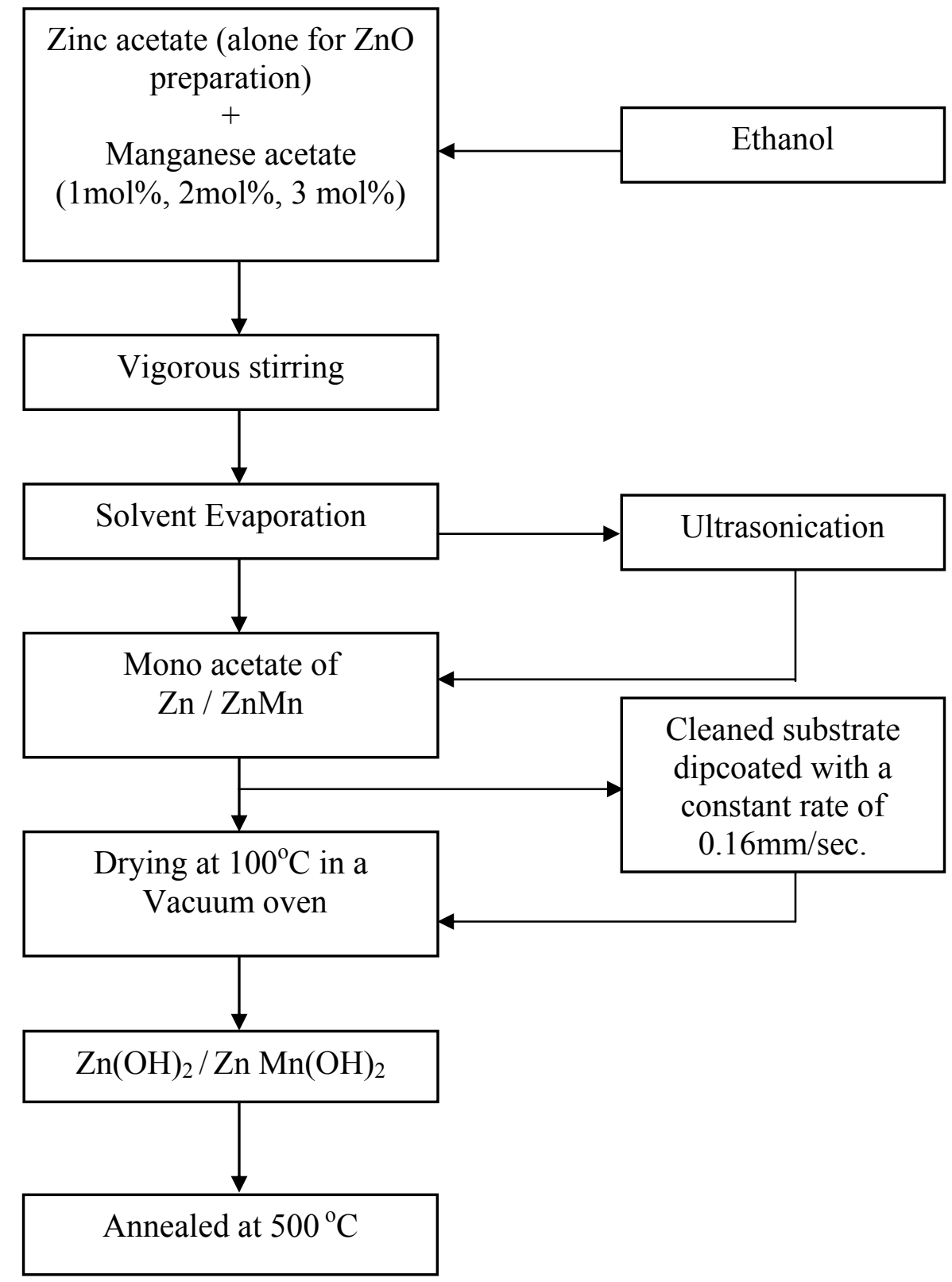

Figure 1: $\quad$ Flow chart describing synthesis of $\mathrm{ZnO}$ and $\mathrm{Mn}$ doped $\mathrm{ZnO}$ 


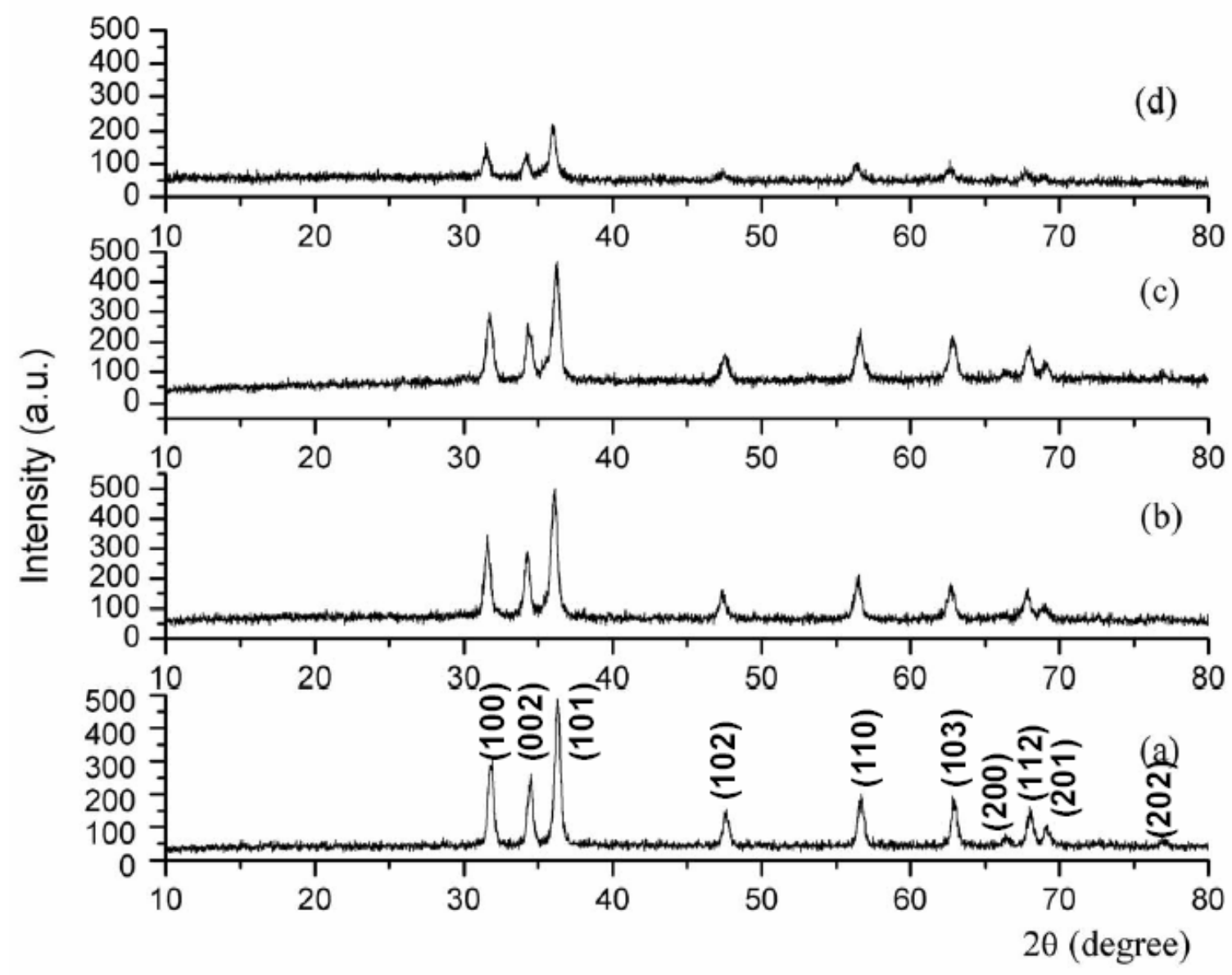

Figure 2: $\quad$ XRD patterns of samples annealed in ambient air at $500^{\circ} \mathrm{C}$ of $1 \mathrm{~h}$. (a) undoped $\mathrm{ZnO}$; (b) $1 \mathrm{~mol} \% \mathrm{Mn}$ doped $\mathrm{ZnO}$; (c) $2 \mathrm{~mol} \% \mathrm{Mn}$ doped $\mathrm{ZnO}$ and (d) $3 \mathrm{~mol} \% \mathrm{Mn}$ doped $\mathrm{ZnO}$. 


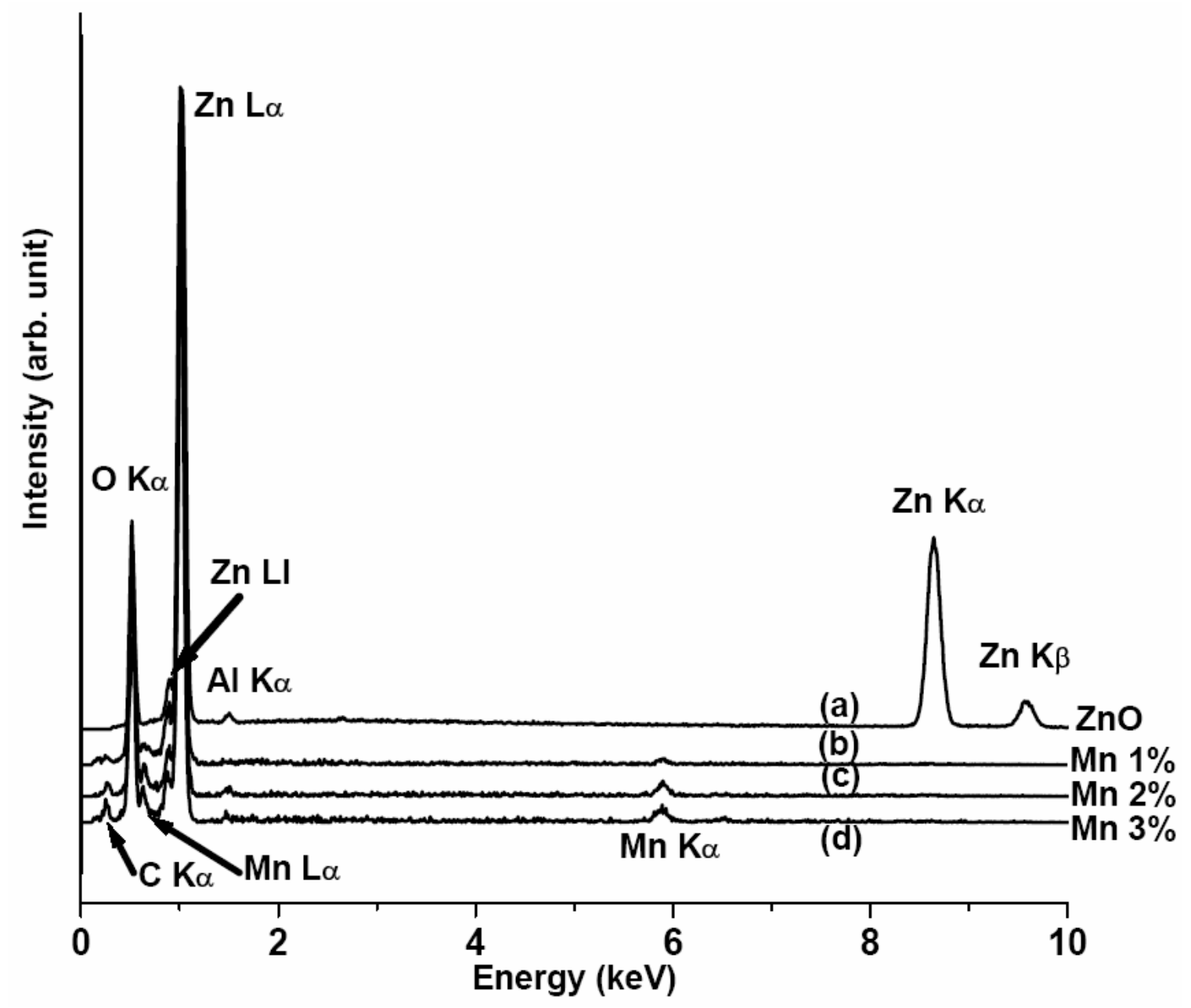

Figure 3: $\quad$ EDX of samples (a-d) annealed in ambient air at $500^{\circ} \mathrm{C}$ of $1 \mathrm{~h}$. 

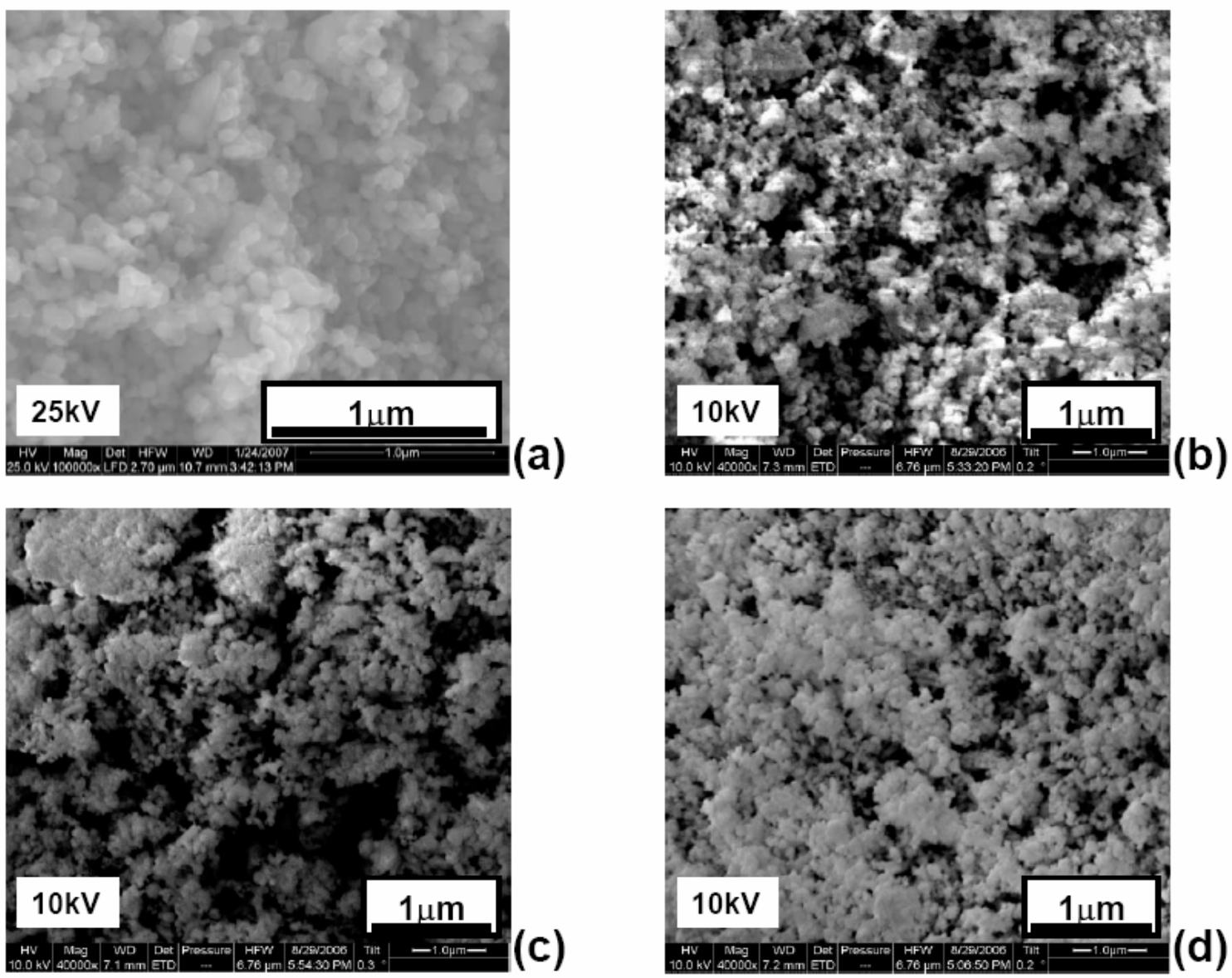

Figure 4: $\quad$ Microstructures of undoped and $\mathrm{Mn}$ doped $\mathrm{ZnO}$ annealed in ambient air at $500^{\circ} \mathrm{C}$ for $1 \mathrm{~h}$ : (a) undoped $\mathrm{ZnO}$; (b) $1 \mathrm{~mol} \%$ Mn doped $\mathrm{ZnO}$; (c) $2 \mathrm{~mol} \%$ $\mathrm{Mn}$ doped $\mathrm{ZnO}$ and (d) $3 \mathrm{~mol} \% \mathrm{Mn}$ doped $\mathrm{ZnO}$. 


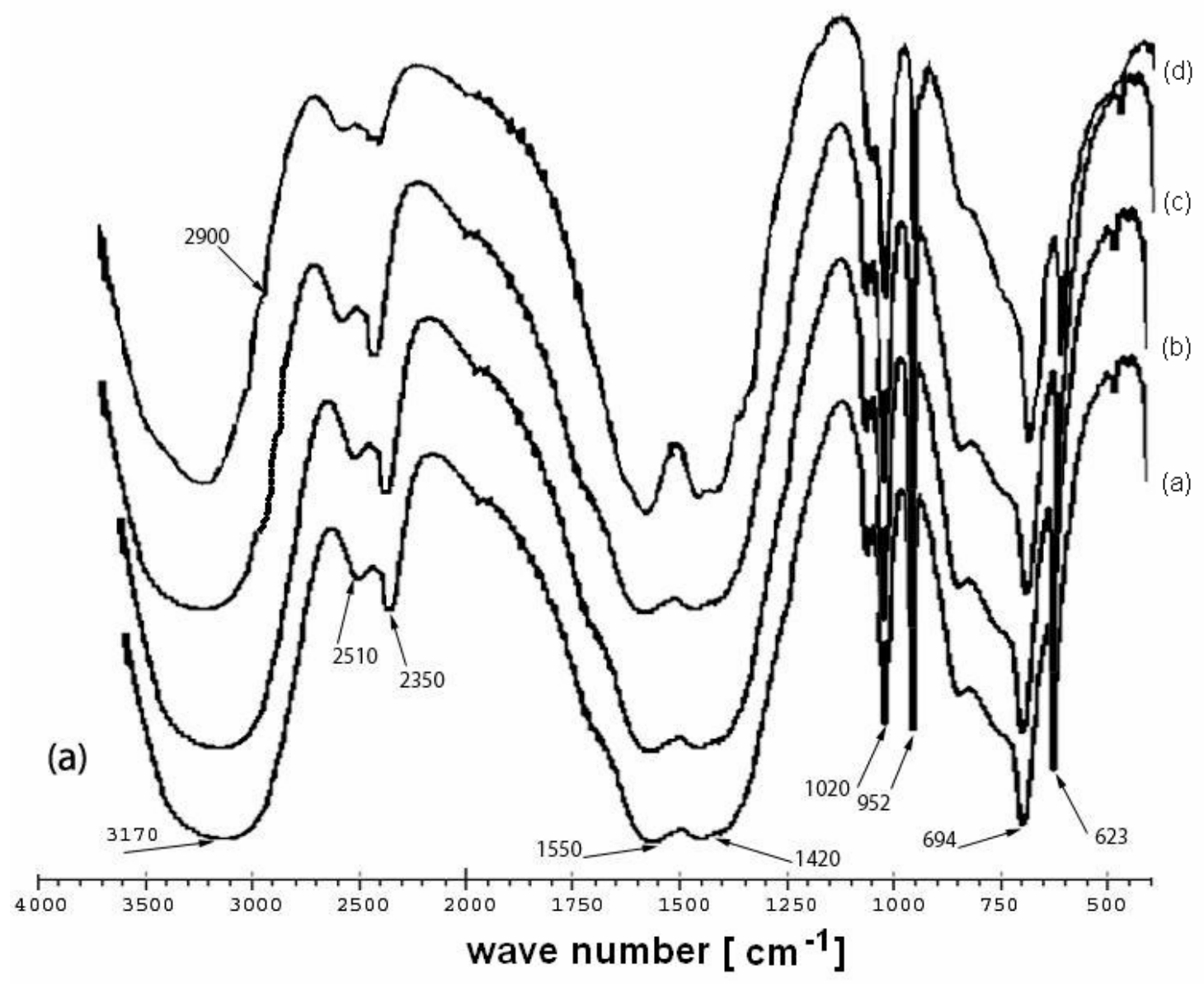

Figure 5(a): $\quad$ FTIR spectra of $100^{\circ} \mathrm{C}$ dried (a) undoped $\mathrm{ZnO}$ and $\mathrm{Mn}$ doped $\mathrm{ZnO}$ :

(b) $1 \mathrm{~mol} \%$ (c) $2 \mathrm{~mol} \%$ (d) $3 \mathrm{~mol} \%$ 


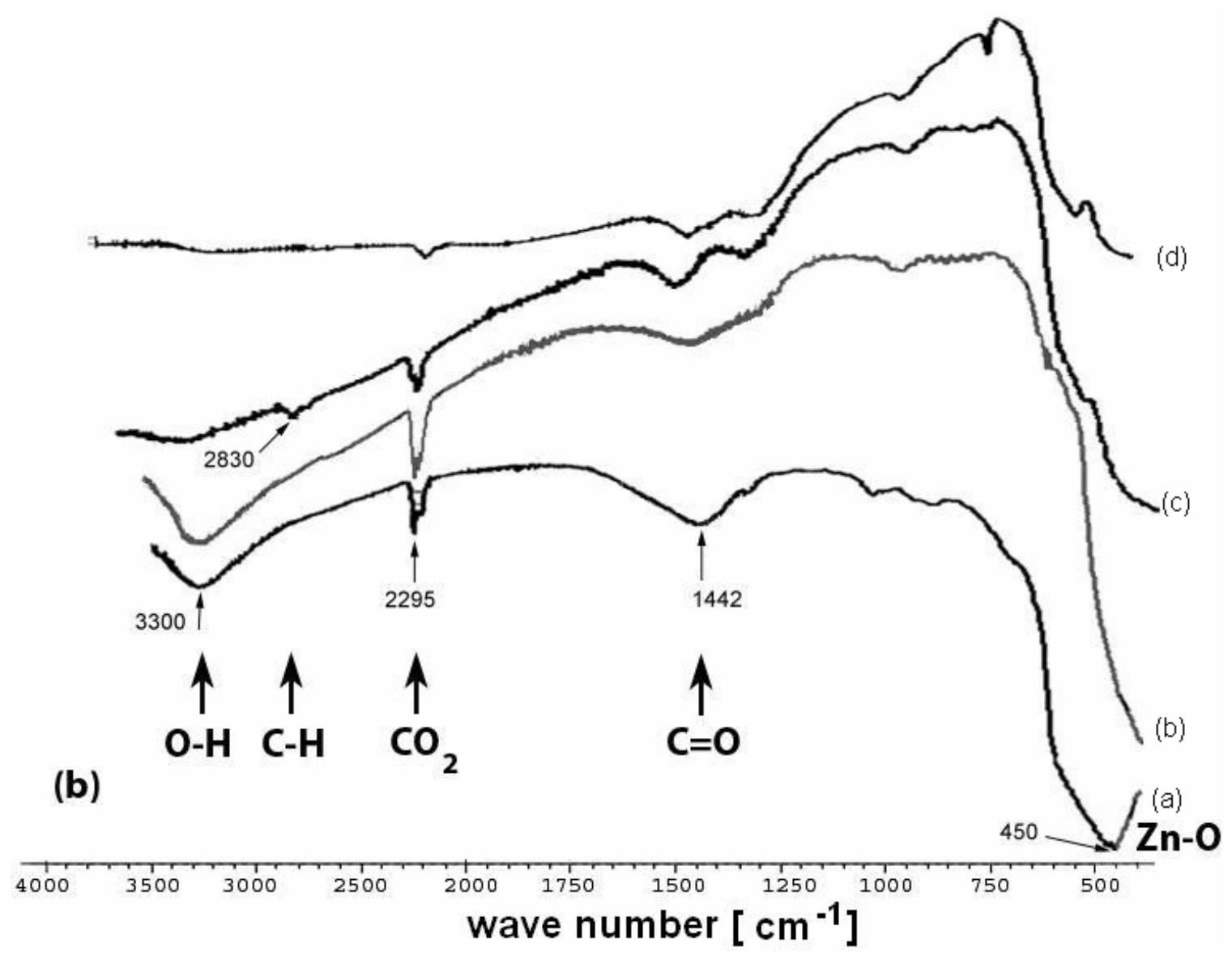

Figure 5(b): FTIR spectra of $500^{\circ} \mathrm{C}$ annealed (a) undoped $\mathrm{ZnO}$ and $\mathrm{Mn}$ doped $\mathrm{ZnO}$ at (b) $1 \mathrm{~mol} \%$ (c) $2 \mathrm{~mol} \%$ and (d) $3 \mathrm{~mol} \%$ 


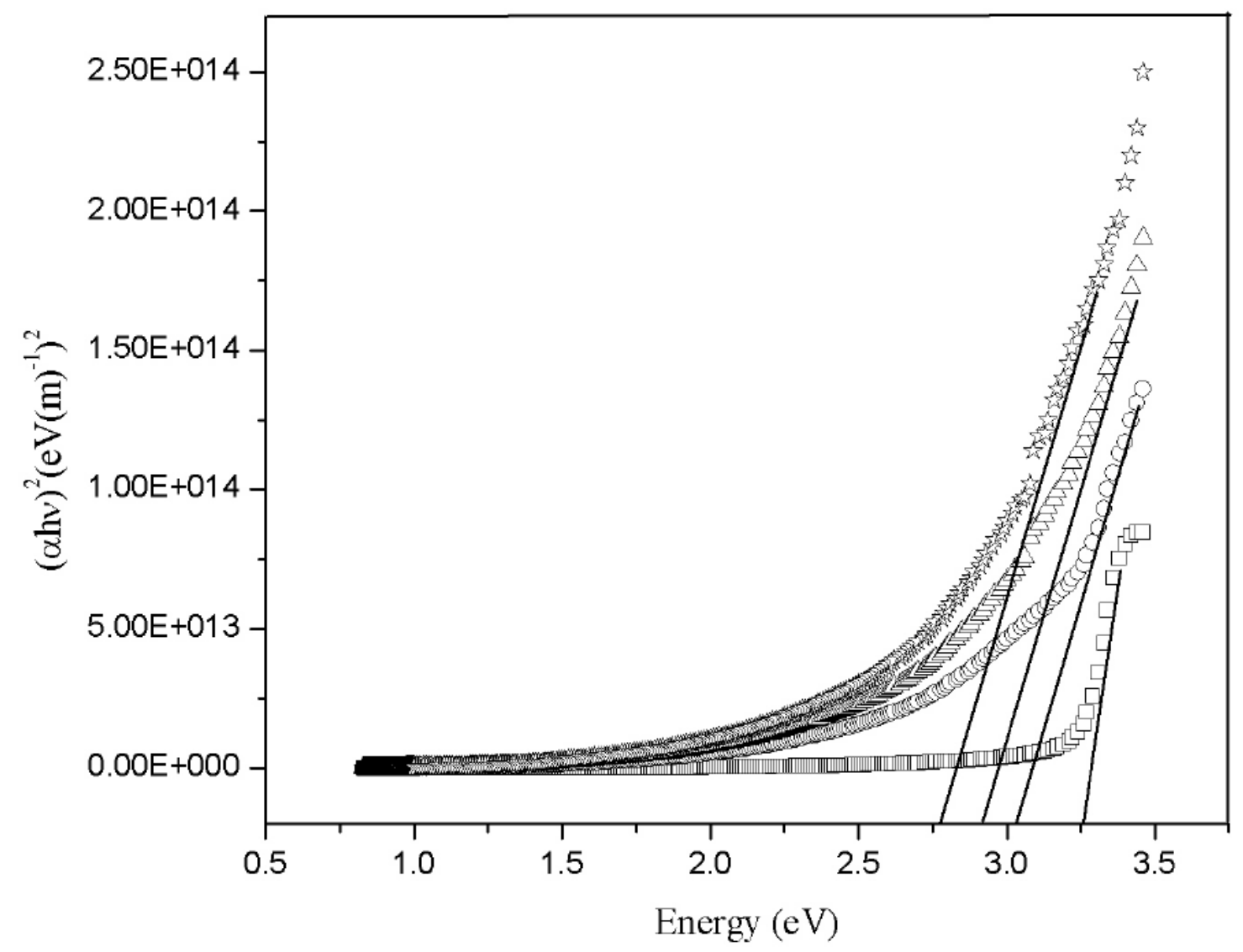

Figure 6: $\quad$ Absorption spectra of: $(\square)$ undoped $\mathrm{ZnO}$; $(\mathrm{O}) 1 \mathrm{~mol} \% \mathrm{Mn}$ doped $\mathrm{ZnO}$; $(\triangle)$ ) $2 \mathrm{~mol} \% \mathrm{Mn}$ doped $\mathrm{ZnO}$; and (沱) $3 \mathrm{~mol} \% \mathrm{Mn}$ doped $\mathrm{ZnO}$. 